\title{
GENOME-WIDE PREDICTION OF HUMAN PAPILLOMA VIRUS SPECIFIC T-CELL EPITOPES USING A COMBINATION OF MATRIX BASED COMPUTATIONAL TOOLS
}

\author{
MANIKANDAN MOHAN, KRISHNAN SUNDAR \\ Department of Biotechnology, Kalasalingam University, Krishnankoil 626126, Tamilnadu, India \\ Email: sundarkr@klu.ac.in
}

Received: 21 Jul 2017 Revised and Accepted: 21 Sep 2017

\section{ABSTRACT}

Objective: To predict the immunogenic epitopes from human papillomavirus (HPV) virus using matrix based computational tools.

Methods: In the present study, three matrix based algorithms, SYFPETHI, BIMAS and RANKPEP were used to predict the cytotoxic T lymphocyte (CTL) epitopes of HPV 16 and 18. The ability of the peptides to bind HLA A_0201, a most common allele, was evaluated using these algorithms. High scoring peptides were considered as potential binders.

Results: Evaluation of HPV 16 proteome resulted in the prediction of 249 peptides as potential binders. Out of these only 25 peptides were predicted as binders by all three algorithms. Analysis of HPV 18 predicted 215 peptides, as potential binders. Among the 215 peptides only 20 peptides were predicted as binders by all three algorithms.

Conclusion: The efficacy of these peptides in inducing a stronger immune response needs to be tested using in vitro and in vivo assays. The identified epitopes could be used in designing a novel epitope vaccine for HPV.

Keywords: Epitope prediction, CTL epitopes, Human papilloma virus, BIMAS, SYFPEITHI, RANKPEP.

(C) 2017 The Authors. Published by Innovare Academic Sciences Pvt Ltd. This is an open access article under the CC BY license (http://creativecommons.org/licenses/by/4.0/) DOI: http://dx.doi.org/10.22159/ijpps.2017v9i11.21523.

\section{INTRODUCTION}

Cervical cancer is the second most common cancer in women worldwide. HPV is the causative agent of cervical cancer and the highest infection rate was reported among young women aged between 15-19 y $[1,2,47]$. The greatest burden of HPV infection occurs in developing countries due to the lack of organized screening programs $[3,4,48]$. In India, it has been reported that 130,000 cases and 70-75,000 death occurred annually, suggesting that the cervical cancer is one of the major cancers in India [5]. Based on the carcinogenicity, HPV can be divided into two groups: high-risk types such as HPV 16 and 18 and low-risk types such as HPV type 6 and 11 [6]. More than 70\% of cervical cancer is caused by both HPV type 16 and 18. Currently, two vaccines (Ceravix and Gardasil) are commercially administrated to prevent HPV infection [46]. These preventative vaccines are mainly used for protection against HPV type 16, 18, 6 and 11 [7]. Administration of these vaccines in some cases leads to severe side effects [8]. Few studies have focused on the development of therapeutic epitope based vaccines using E5, E6, L1 and L2 proteins $[9,10]$.

CD4 and CD8 T cell responses play an important role in controlling the pathogenesis of HPV in human [11]. The accurate identification of CTL epitopes is a critical step towards the development of peptide vaccine [12]. The identification of CTL epitopes could be accelerated using in silico prediction methods [13]. Major histo-compatability complex (MHC) molecules play a major role in the activation of Tcell mediated immune response [14]. Processing and presentation of epitopes via MHC to CTL are an important process for immuno surveillance against various pathogens [15]. Antigenic proteins are cleaved in the proteosomes into shorter peptides, which are loaded on to class I MHC molecules [13] and exported to the cell surface for presentation to the T-cell receptor $[16,43]$. TAP proteins also play a role in this antigen presentation [17]. It was estimated that only one peptide out of 200 peptides could bind to the MHC class I MHC molecules and elicit CTL response [18]. The development of the multivalent vaccine that enhances cytotoxic $\mathrm{T}$ cell immunity is a major direction of research in current vaccine development [19].

Many computational algorithms have been developed for predicting the binding of peptides to MHC molecules $[20,21]$ including quantitative matrices [22, 23], factal neural netw orks [24], hidden-markov models [25] and molecular modelling [26, 27]. These approaches could be used for prediction of antigenic epitopes. Few of them are open source algorithms such as BIMAS [28], SYFPEITHI [22], RANKPEP [29], SVMHC [30] and MHCPRED [31]. In the present study, the specificity and sensitivity of some of the tools in predicting epitopes were evaluated and the combinations of tools were used for predicting the immunogenic CTL epitopes in HPV proteome.

\section{MATERIALS AND METHODS}

\section{Source data}

In the present study, the sensitivity and the specificity of the algorithms were evaluated by known binders and non-binding peptides. A set of 311 known binders were obtained from the HIV epitope database of Los Alamos National Laboratory and immune epitope database (IEDB). Totally 222 non-binding peptides were derived from MHCBN and IEDB. The complete set of HPV type 16 and 18 proteins (Early proteins E1, E2, E5, E6 and E7; Late proteins L1 and L2) were retrieved from Gen Bank (http://www. ncbi. nlm. nih. gov/genbank/) database and the details are provided in table 1.

\section{Tools used for prediction of HPV 16 and 18 CTL epitopes}

The complete set of HPV type 16 and 18 proteomes were analyzed for the MHC class I HLA A_0201 binding peptides using three matrix based prediction algorithms namely BIMAS (http://wwwbimas.cit.nih.gov/molbio/hla_bind/), SYFPEITHI (http://www. syfpeithi.de/) and RANKPEP (http://imed.med. ucm.es/Tools /rankpep.html). All individual protein sequences of HPV serotypes 16 and 18 were parsed into the algorithms, and the binding efficiencies of the nine amino acid peptides were calculated.

\section{Calculation of sensitivity and specificity of the algorithms}

For the calculation of sensitivity and specificity, each binding and non-binding peptides were individually analyzed by using three matrix based algorithms (SYFPEITHI, BIMAS, and RANKPEP) and the results were computed. The cut-off score for binding of these peptides to the HLA A_0201 was fixed $\underset{2}{20} 2050$ and $\geq 60$ for 
SYFPEITHI, BIMAS and RANKPEP respectively. A peptide scoring less than this was considered as a non-binder.

The sensitivity of the computational algorithms [13, 34] was calculated using the formula:

$$
\text { Sesitivity }=\frac{\text { Truepositive }}{\text { True positive+False negative }}(1)
$$

The specificity of the computational algorithms [32, 44] was calculated using the formula:

$$
\text { Specificity }=\frac{\text { Truenegative }}{\text { True negative+False positive }}(2)
$$

\section{Overlapping epitope prediction}

Instead of using a single prediction tools for MHC-peptide binding prediction, using a combination of prediction tools could improve the efficiency of epitope prediction. A peptide predicted as an epitope in more than one tool was considered to be an overlapping epitope. The binders predicted in all three prediction tools were further manually compared with one another for the prediction of overlapping epitopes.

\section{Identification of consensus epitopes}

A peptide which is present in more than one genotype was considered to be a consensus epitope. Based on the occurrence, all predicted binders of HPV 16 and 18 were compared with one another for prediction of consensus epitopes. The level of conservation (single amino acid variation) in predicted epitopes was also assessed among the HPV 16 and 18 genotypes.

\section{Molecular docking}

Molecular docking studies were carried out using AutoDock4.2. The crystal structure of human HLA-A2 (PDB ID: 4NO3) was downloaded from the Protein Data Bank. A known CTL epitope from influenza virus, GILGFVFTL, was taken as a reference peptide. Two predicted binders from this study, QLFVTVVDT (QLF) and KLPQLCTEL (KLP) along with the reference peptide were docked against HLA-A2.

\section{RESULTS}

\section{Sensitivity and specificity of the algorithm}

When the known binders for HLA A_0201 were analyzed, BIMAS could predict only 176 out of 311 with a sensitivity of $57.56 \%$. The sensitivity of SYFPEITHI and RANKPEP was calculated as $77.49 \%$ and $67.52 \%$ respectively. The combination of more than one algorithm improved the sensitivity; SYFPEITHI and BIMAS when combined together could predict 252 of the 311 peptides with a sensitivity of 81.02\%; However, combining all the three programs increased the sensitivity from $57.56 \%$ to $81.99 \%$ ( 255 out of 311 ) (fig. 1).

\begin{tabular}{|c|c|c|c|c|c|}
\hline \multirow[t]{2}{*}{ S. No. } & \multirow[t]{2}{*}{ Protein } & \multicolumn{2}{|c|}{ Total number of amino acids } & \multicolumn{2}{|c|}{ Number of peptides analyzed } \\
\hline & & HPV 16 & HPV 18 & HPV 16 & HPV 18 \\
\hline 1 & E1 & 649 & 657 & 641 & 649 \\
\hline 2 & $\mathrm{E} 2$ & 365 & 365 & 357 & 357 \\
\hline 3 & $\mathrm{E} 4$ & 95 & 88 & 87 & 80 \\
\hline 4 & E5 & 83 & 73 & 75 & 65 \\
\hline 5 & E6 & 158 & 158 & 150 & 158 \\
\hline 6 & E7 & 98 & 105 & 90 & 97 \\
\hline 7 & L1 & 531 & 568 & 523 & 560 \\
\hline 8 & L2 & 473 & 462 & 465 & 454 \\
\hline
\end{tabular}

Table 1: Overview of epitope prediction analysis in HPV 16 and 18 proteomes

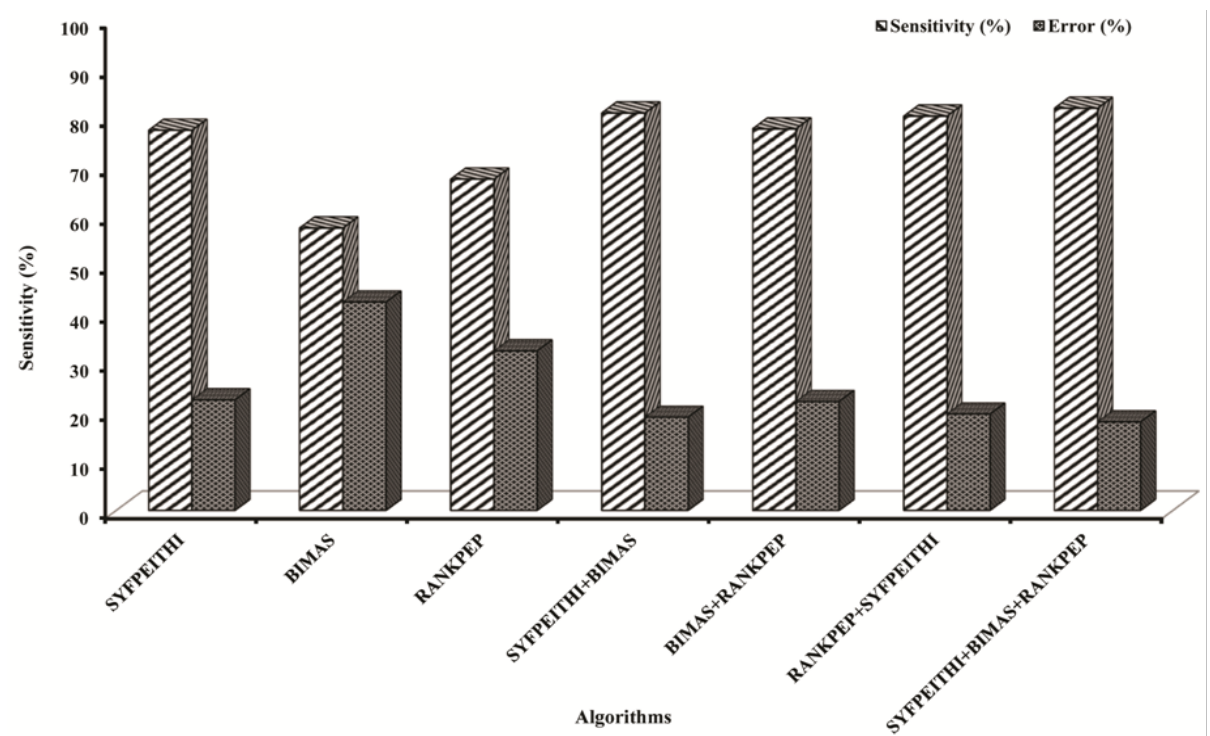

Fig. 1: Sensitivity of the selected algorithms in the prediction of CTL epitopes. The sensitivity of individual algorithms (SYFPEITHI, BIMAS and RANKPEP) and the combination were analyzed. Sensitivity increased $(81.99 \%)$ when all the three algorithms were combined with a minimal error rate

Based on the cut-off criteria, each of the non-binders was tested using all three algorithms and based on the results the specificity was calculated based on the formula described in method's section. When 222 non-binders were analyzed, the specificities of BIMAS, SYFPEITHI and RANKPEP were 93.69\%, $77.03 \%$ and $74.78 \%$ respectively. The specificity were improved when a combination of two or more algorithms were used (fig. 2). 


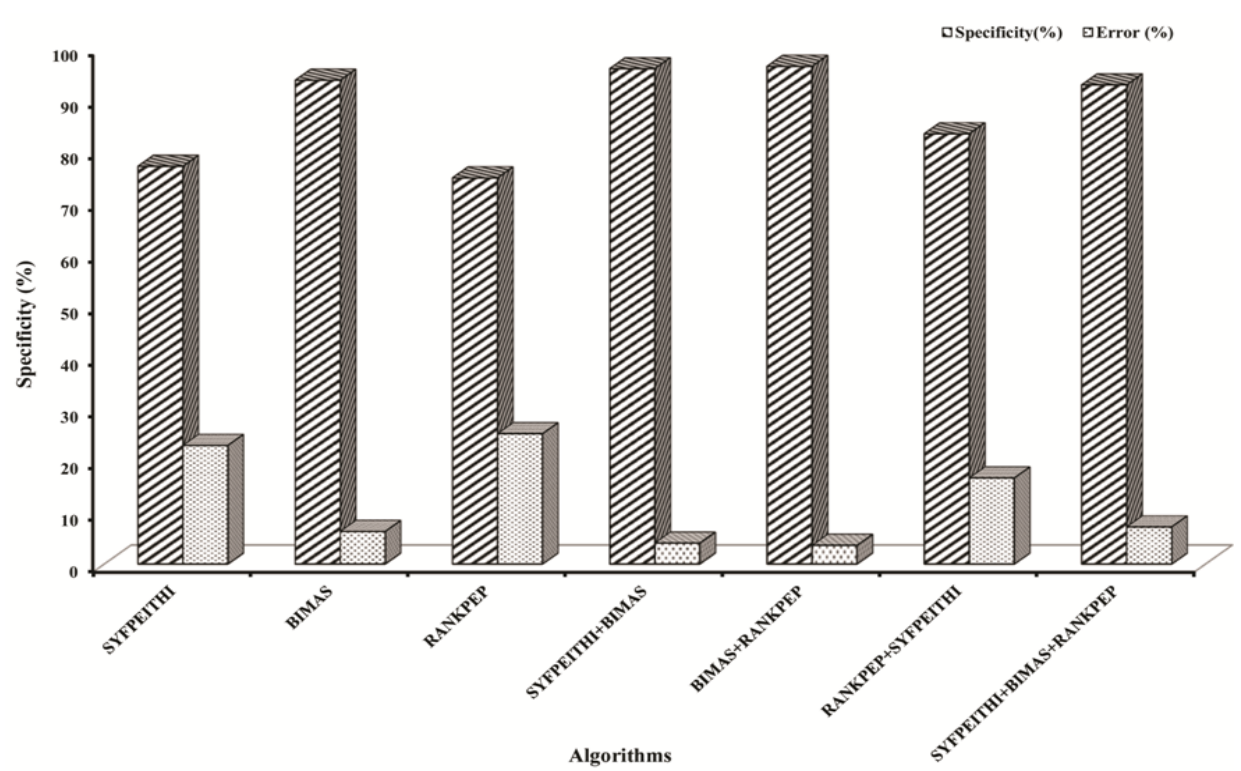

Fig. 2: Specificity of the selected algorithms in the prediction of CTL epitopes. Specificity of individual algorithms (SYFPEITHI, BIMAS and RANKPEP) and the combination was calculated using known non-binders. Improved specificity was observed when two or more of the algorithms were used in combination

\section{HPV 16 and 18 epitope mapping}

The proteomes of HPV type 16 and 18 serotypes were analyzed for the prediction of CTL epitopes using all the three algorithms. In HPV 16, a total of 2388 peptides were analyzed, and 249 of them were predicted as binders by all three algorithms together (fig. 3D). SYFPEITHI alone could predict 115 peptides as binders (fig. 3A), where as 45 and 89 binders were predicted by BIMAS and RANKPEP respectively (fig. 3B and 3C).

When 2412 peptides were analyzed in HPV 18 proteome, all the three algorithms together predicted 215 peptides as binders (fig. 4D). In which, 102, 44 and 69 binders were predicted by SYFPEITHI (fig. 4A), BIMAS (fig. 4B) and RANKPEP (fig. 4C) respectively.
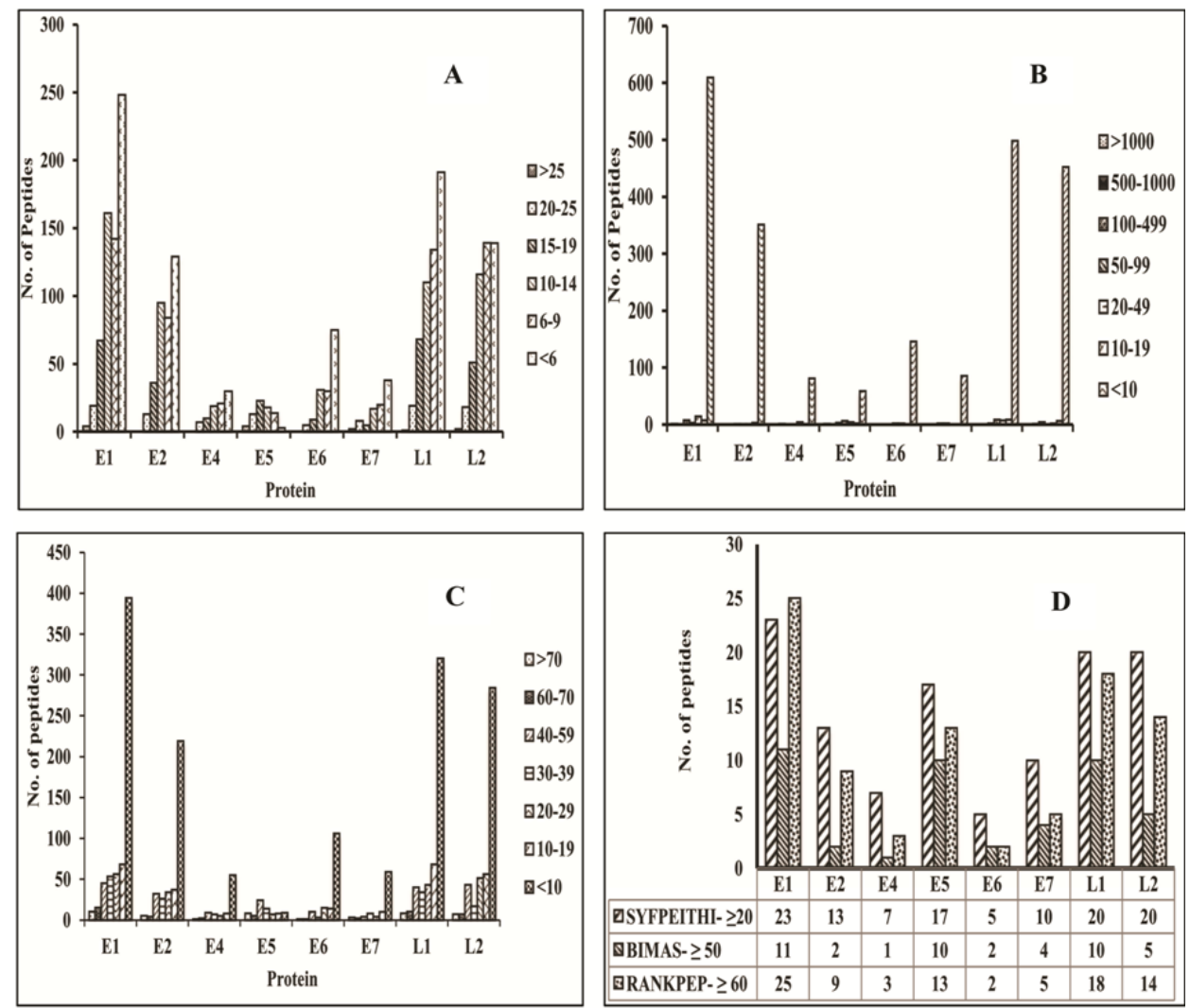

Fig. 3: Prediction of CTL epitopes for HPV 16 serotype. H. PV 16 serotype proteins were analyzed by SYFPEITHI, BIMAS and RANKPEP. A. Analysis of the proteome of HPV 16 by SYFPEITHI. B. Analysis of the proteome of HPV 16 by BIMAS analysis C. Analysis of the proteome of HPV 16 by RANKPEP D. Prediction of peptides as binders in HPV 16 proteome using SYFPETHI, BIMAS and RANKPEP algorithms based on the fixed criteria 

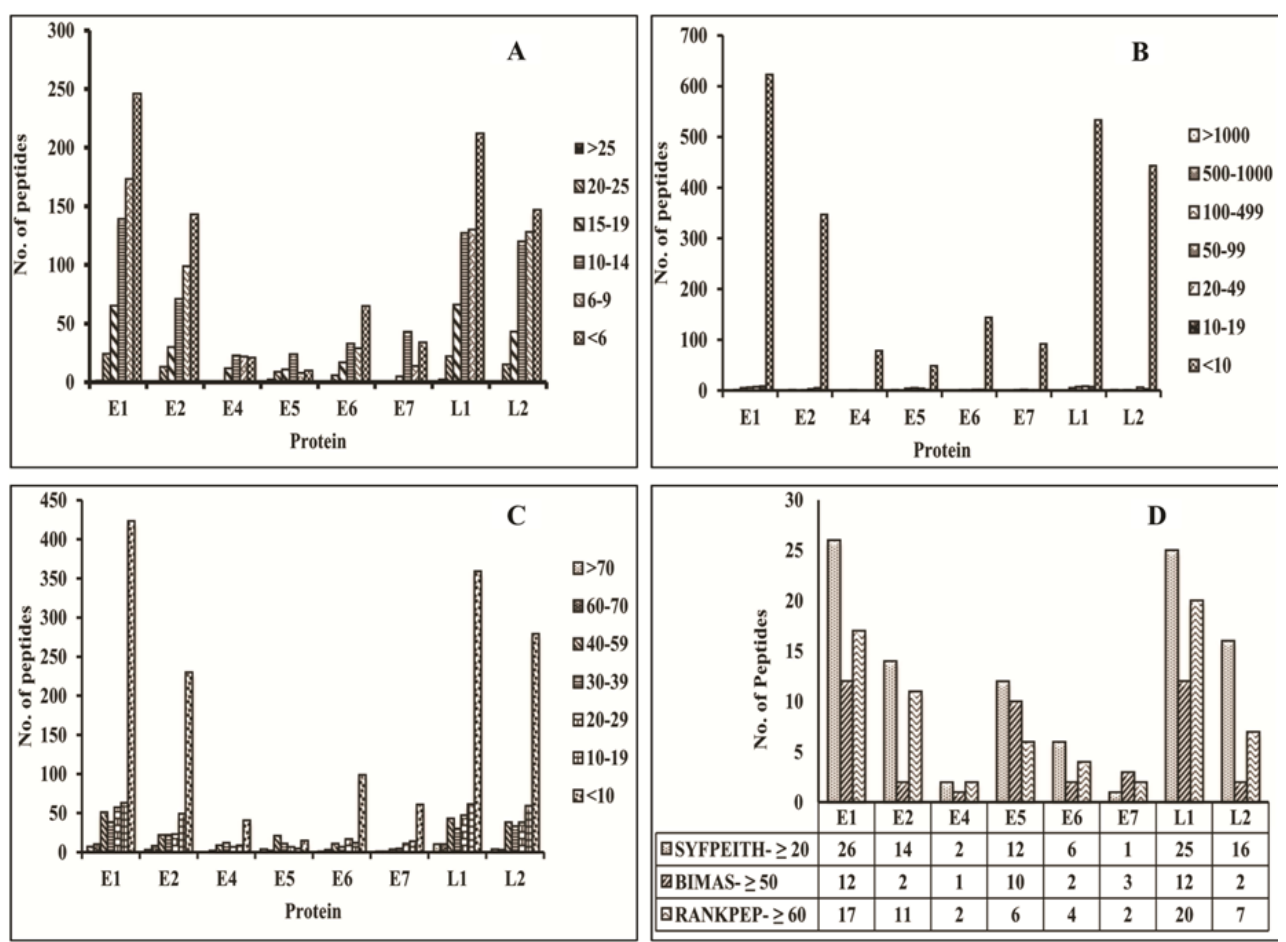

Fig. 4: Prediction of CTL epitopes for HPV 18 serotype. HPV 18 serotype proteins were analysed by SYFPEITHI, BIMAS and RANKPEP. A. Analysis of the proteome of HPV 18 by SYFPEITHI. B. Analysis of the proteome of HPV 18 by BIMAS analysis. C. Analysis of the proteome of HPV 18 by RANKPEP. D. Prediction of peptides as binders in HPV 18 proteome using SYFPETHI, BIMAS and RANKPEP algorithms based on the fixed criteria

\section{Overlapping epitope prediction}

Though 249 peptides were found to be predicted as binders by the three matrix based algorithms viz. BIMAS, SYFPEITHI and RANKPEP, only 25 of them were considered as overlapping peptides in HPV 16 proteome as predicted by all three prediction tools. The highest number of overlapping peptides were predicted in E1 and L1 proteins (table 2). Likewise, 20 overlapping binders were predicted in HPV 18 analysis and L1 protein showed the highest number of overlapping peptides (table 3).

Table 2: Predicted CTL epitopes in HPV 16 proteome

\begin{tabular}{|c|c|c|c|c|c|}
\hline Protein & Accession No. & Peptide Sequence & $\begin{array}{l}\text { SYFPEITHI } \\
\text { score }\end{array}$ & $\begin{array}{l}\text { BIMAS } \\
\text { score }\end{array}$ & $\begin{array}{l}\text { RANKPEP } \\
\text { score } \\
\end{array}$ \\
\hline \multirow[t]{6}{*}{ E1 } & P03114 & KLLSKLLCV & 29 & 2071.606 & 93 \\
\hline & & YLVSPLSDI & 25 & 110.379 & 89 \\
\hline & & LLQQYCLYL & 24 & 199.738 & 81 \\
\hline & & CLYLHIQSL & 27 & 157.227 & 72 \\
\hline & & AMLAKFKEL & 24 & 108.462 & 69 \\
\hline & & FLTALKRFL & 21 & 108.094 & 65 \\
\hline \multirow[t]{2}{*}{ E2 } & P03120 & TLQDVSLEV & 24 & 285.163 & 97 \\
\hline & & TLYTAVSST & 21 & 54.847 & 80 \\
\hline \multirow[t]{3}{*}{ E5 } & P06927 & VLLCVCLLI & 22 & 65.622 & 78 \\
\hline & & IILVLLLWI & 26 & 114.142 & 75 \\
\hline & & FLLCFCVLL & 26 & 1381.635 & 68 \\
\hline E6 & P03126 & KLPQLCTEL & 24 & 74.768 & 68 \\
\hline \multirow[t]{3}{*}{ E7 } & P03129 & LLMGTLGIV & 29 & 53.631 & 92 \\
\hline & & TLHEYMLDL & 24 & 201.447 & 86 \\
\hline & & RLCVQSTHV & 20 & 69.552 & 75 \\
\hline \multirow[t]{6}{*}{ L1 } & P03101 & TLQANKSEV & 22 & 69.552 & 81 \\
\hline & & ILVPKVSGL & 30 & 83.527 & 75 \\
\hline & & YLRREQMFV & 22 & 133.735 & 73 \\
\hline & & GLQYRVFRI & 22 & 139.174 & 70 \\
\hline & & QLFVTVVDT & 21 & 63.417 & 62 \\
\hline & & RLVWACVGV & 23 & 69.552 & 62 \\
\hline \multirow[t]{4}{*}{$\mathrm{L} 2$} & P03107 & SLVEETSFI & 24 & 235.26 & 96 \\
\hline & & YLHPSYYML & 25 & 147.401 & 76 \\
\hline & & AILDINNTV & 26 & 145.077 & 77 \\
\hline & & ILQYGSMGV & 24 & 118.238 & 64 \\
\hline
\end{tabular}


Table 3: Predicted CTL epitopes in HPV 18 proteome

\begin{tabular}{|c|c|c|c|c|c|}
\hline Protein & Accession no. & Peptide sequence & SYFPEITHI score & BIMAS score & RANKPEP score \\
\hline \multirow[t]{2}{*}{ E1 } & P06789 & ILYAHIQCL & 27 & 267.286 & 75 \\
\hline & & FLGALKSFL & 22 & 540.469 & 69 \\
\hline $\mathrm{E} 2$ & P06790 & TLSERLSCV & 26 & 655.875 & 88 \\
\hline E4 & P06791 & RLLHDLDTV & 28 & 290.025 & 70 \\
\hline \multirow[t]{4}{*}{ E5 } & P06792 & VLVFVYIVV & 20 & 72.717 & 82 \\
\hline & & MLLLHIHAI & 26 & 150.931 & 80 \\
\hline & & LLLHIHAIL & 26 & 55.091 & 67 \\
\hline & & WVLVFVYIV & 22 & 371.17 & 64 \\
\hline E6 & P06463 & KLPDLCTEL & 25 & 306.55 & 70 \\
\hline E7 & P06788 & TLQDIVLHL & 26 & 201.447 & 94 \\
\hline \multirow[t]{8}{*}{ L1 } & P06794 & SLVDTYRFV & 23 & 470.519 & 90 \\
\hline & & CLYTRVLIL & 26 & 64.463 & 86 \\
\hline & & TLQDTKCEV & 23 & 285.163 & 80 \\
\hline & & ILFLRNVNV & 25 & 437.482 & 71 \\
\hline & & YIILFLRNV & 27 & 76.897 & 68 \\
\hline & & VLILHYHLL & 24 & 54.474 & 64 \\
\hline & & QLFVTVVDT & 21 & 63.417 & 62 \\
\hline & & RLVWACAGV & 23 & 69.552 & 62 \\
\hline \multirow[t]{2}{*}{$\mathrm{L} 2$} & P06793 & TLIEDSSVV & 24 & 116.917 & 88 \\
\hline & & YLWPLYYFI & 25 & 3286.176 & 69 \\
\hline
\end{tabular}

Table 4: Consensus epitopes predicted in HPV 16 and 18

\begin{tabular}{ll|l}
\hline HPV protein & Amino acid position/Peptide Sequence \\
\hline & 123 & 354 \\
HPV 16_L1 & RLVWACVGV & QLFVTVVDT \\
HPV 18_L1 & RLVWACAGV & \\
& 18 & \\
HPV 16_E6 & KLPQLCTEL & \\
HPV 18_E6 & KLPDLCTEL & \\
& & \\
\end{tabular}

Letters in BOLD indicates single amino acid variation in HPV 16 and 18.

\section{Identification of consensus peptide}

A total of 45 overlapping peptides were predicted in this study, among five peptides were considered as consensus peptides (table 4); $100 \%$ sequence similarity was found in L1 peptideQLFVTVVDT $354-662$ and four other peptides exhibited a single amino acid variation (HPV 16 E6 peptide-KLPQLCTEL ${ }_{18-29}$ and L1 peptideRLVWACVGV $_{123-131} ;$ HPV 18 E6 peptide-KLPDLCTEL $L_{13-21}$ and L1 peptide-RLVWACAGV $158-66)$.

\section{Molecular docking}

The reference peptide binds with HLA-A2 with a binding energy of$2.37 \mathrm{kcal} / \mathrm{mol}$ and the interaction is mediated through two hydrogen bonds. The peptides, QLF and KLP, bind with HLA-A2 with the binding energies of $-3.57 \mathrm{kcal} / \mathrm{mol}$ and $-3.55 \mathrm{kcal} / \mathrm{mol}$ respectively, indicating that these two predicted peptides bind efficiently than the reference peptide.

The interaction of QLF with HLA-A2 is through five hydrogen bonds (fig. 5), whereas the interaction of the reference peptide is only by two hydrogen bonds; this confirms that the binding of QLF is stronger than that of the reference peptide. The interacting residues are presented in table 5. The binding poses of the QLF peptide along with the reference peptide is shown in fig. 6 . This indicates that the QLF peptide binds at the same binding site (peptide binding groove) where the reference peptide binds.

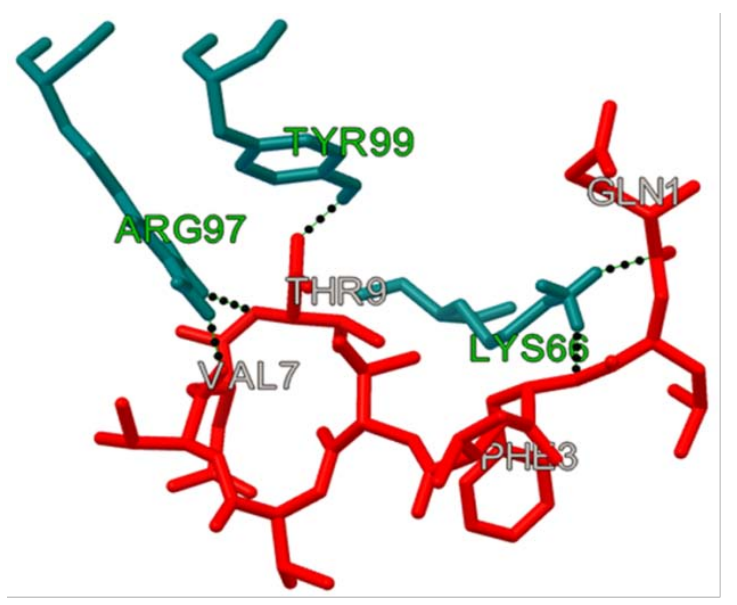

Fig. 5: Interactions of QLF with HLA-A2 


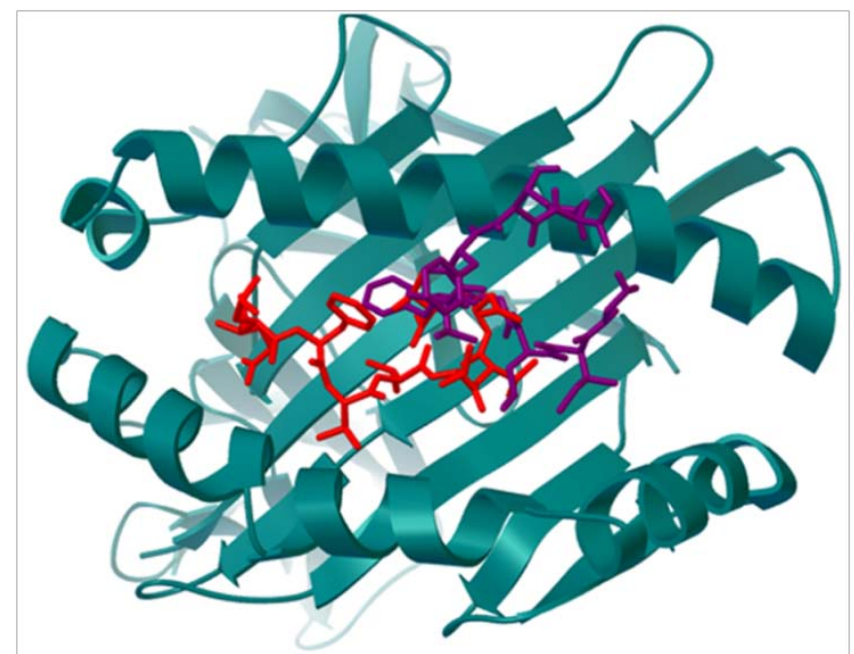

Fig. 6: Binding of QLF peptide and the reference peptide with HLA-A2

Table 5: Interaction of consensus peptides with MHC

\begin{tabular}{|c|c|c|c|}
\hline Peptide & $\begin{array}{l}\text { Binding energy } \\
\text { (kcal/mol) }\end{array}$ & No of hydrogen bonds formed & $\begin{array}{l}\text { Interacting residues } \\
\text { (MHC } \rightarrow \text { Peptide) }\end{array}$ \\
\hline GILGFVFTL (Reference peptide from influenza) & -2.37 & 2 & $\begin{array}{l}\text { Arg97 } \rightarrow \text { Val6 } \\
\text { Trp147 } \rightarrow \text { Leu3 }\end{array}$ \\
\hline QLFVTVVDT (QLF) & -3.57 & 5 & $\begin{array}{l}\text { Tyr99 } \rightarrow \text { Thr9 } \\
\text { Arg97 } \rightarrow \text { Val7 } \\
\text { Lys66 } \rightarrow \text { Gln1 } \\
\text { Arg97 } \rightarrow \text { Thr9 } \\
\text { Lys66 } \rightarrow \text { Phe3 }\end{array}$ \\
\hline KLPQLCTEL (KLP) & -3.55 & 2 & $\begin{array}{l}\text { Arg65 } \rightarrow \text { Glu8 } \\
\text { Arg97 } \rightarrow \text { Leu9 }\end{array}$ \\
\hline
\end{tabular}

\section{DISCUSSION}

Modern immunoinformatics tools provide the new platform for designing peptide vaccines against pathogenic microorganisms [33]. Though many tools are available for predicting immunogenic CTL epitopes, the accuracy of any of these tools is not appreciative. Hence with a concept that a combination of two or more tools could solve the problem [45]; this study was undertaken with three well-known matrix based algorithms. The specificity and sensitivity of the algorithms were evaluated using a known set of binders and nonbinders, and the results indicated that combination of algorithms increased the specificity without affecting the sensitivity of the tested tools.

Based on this approach, a total of $249(10.42 \%)$ binders were predicted out of 2388 peptides in HPV 16. Similarly, 215 (8.91\%) binders were predicted out of 2412 peptides analyzed in HPV 18. Among the predicted epitopes, 45 were promiscuous overlapping peptides that were predicted by all three algorithms. Some of the peptides predicted in the study were already reported as CTL epitopes. HPV 16 peptides E1-LLQQYCLYL 254-262 [34], E5FLLCFCVLL $_{15-23}$, VLLCVCLLI $_{21-29}$ [35], E6-KLPQLCTEL $18-26[36,37]$ and E7-TLHEYMLDL7-15 [38] are known CTL epitopes. E7LLMGTLGIV $_{82-90}$ was known to induce the cellular response in HLA A2.1 rabbit model [39] and reduced tumor burden in aged mice [40]. E6-KLPDLCTEL 13-22 [41] and E7-TLQDIVLHL 7-15 [42] were proved to be CTL epitopes for HPV 18.

One of the predicted peptides, QLFVTVVDT ${ }_{354-662}$ from L1 protein is conserved in both HPV 16 and 18 genotypes. Peptide KLPQLCTEL ${ }_{18}$ ${ }_{26}$ from E6 has a single amino acid variation in the fourth position; the variation glutamine (HPV 16) instead of aspartic acid (HPV 18) has already been reported [8]. Similarly, alanine (HPV 16) instead of valine (HPV 18) was observed in L1-RLVWACAGV ${ }_{158-166}$ at the 7 th position. The results were further confirmed using docking studies of the peptide with the MHC.

\section{CONCLUSION}

The results of the present study revealed the use of computational algorithms in the prediction of CTL epitopes based on the binding to MHC Class I MHC molecules. Combination of more than one tool increases the chance to predict potent CTL epitopes against viral diseases. Using this approach few epitopes were predicted for HPV 16 and 18. Further confirmation of the efficacy of these epitopes in inducing a stronger immune response needs to be done based on in vitro and in vivo assays

\section{ACKNOWLEDGEMENT}

The work was supported by a grant from Science and Engineering Research Board, New Delhi (SR/SO/HS-0248/2012) to Krishnan Sundar. Manikandan Mohan thank Indian Council of Medical Research, New Delhi for a Senior Research Fellowship (45/18/2011IMM-BMS). The authors thanks, Mrs. J. Christina Rosy for her help in docking studies.

\section{AUTHORS CONTRIBUTION}

All the in silico analyses and written part of the manuscript was carried out by the first author Mr. Manikandan Mohan. The study was conceived, designed, correction and communications of the manuscript were done by the corresponding author Prof. Krishnan Sundar.

\section{CONFLICT OF INTERESTS}

The authors declared that they have no conflict of interests

\section{REFERENCES}

1. Garland SM, Smith JS. Human papilloma virus vaccines. Drugs 2010;70:1079-98

2. Gatto M, Agmon-Levin N, Soriano A, Manna R, Maoz-Segal R, Kivity S, et al. Human papilloma virus vaccine and systemic lupus erythematosus. Clin Rheumatol 2013;32:1301-7. 
3. Soliman PT, Slomovitz BM, Wolf JK. Mechanism of cervical cancer. Drug Discovery Today: Dis Mech 2004;1:253-8.

4. Schiffman M, Castle PE. Human papilloma virus: epidemiology and public health. Arch Pathol Lab Med 2003;127:930-4.

5. Agarwal SM, Raghav D, Singh H, Raghava GPS. CCDB: a curated database of genes involved in cervix cancer. Nucleic Acids Res 2011;39:975-9.

6. Glahder JA, Hansen CN, Vinther J, Madsen BS, Norrild B. A promoter within the E6 ORF of human papilloma virus type 16 contributes to the expression of the E7 oncoprotein from a monocistronic mRNA. J Gen Virol 2003;84:3429-41.

7. Vu LT, Bui D, Le HT. Prevalence of cervical infection with HPV type 16 and 18 in Vietnam: implications for vaccine campaign. BMC Cancer 2013;13:1-7.

8. Nirmala S, Sudandiradoss C. Prediction of promiscuous epitopes in the E6 protein of three high risk human papilloma viruses: a computational approach. Asian Pac J Can Prev 2013;14:4167-75

9. Yao Y, Huang W, Yang X, Sun W, Liu X, Cun W, et al. HPV-16 E6 and $\mathrm{E} 7$ protein $\mathrm{T}$ cell epitopes prediction analysis based on distributions of HLA-A loci across populations: an in silico approach. Vaccine 2013;31:2289-94.

10. Suzich JA, Ghim SJ, Palmer-Hill FJ, White WI, Tamura JK, Bell JA, et al. Systemic immunization with papilloma virus L1 protein completely prevents the development of viral mucosal papillomas. Proc Natl Acad Sci 1995;92:11553-7.

11. Van der Burg SH, de Jong A, Welters MJ, Offringa R, Melief CJ. The status of HPV16-specific T-cell reactivity in health and disease as a guide to HPV vaccine development. Virus Res 2002;89:275-84.

12. Sette A, Newman M, Livingston B, McKinney D, Sidney J, Ishioka $\mathrm{G}$, et al. Optimizing vaccine design for cellular processing, $\mathrm{MHC}$ binding and TCR recognition. HLA 2002;59:443-51.

13. Irini AD, Guan P, Flower DR. EpiJen: a server for multistep T cell epitope prediction. BMC Bioinformatics 2006;7:131.

14. Hudson AW, Ploegh HL. The cell biology of antigen presentation. Exp Cell Res 2002;272:1-7.

15. Srinivasan KN, Zhang GL, Khan AM, August JT, Brusic V. Prediction of class I T-cell epitopes: evidence of presence of immunological hot spots inside antigens. Bioinformatics 2004;20:297-302.

16. Van Kaer L. Major history compatibility complex class restricted antigen processing and presentation. Tissue Antigens 2002;60:1-9.

17. Larsen MV, Lundegaard C, Lamberth K, Buus S, Brunak S, Lund 0 , et al. An integrative approach to CTL epitope prediction: a combined algorithm integrating MHC class I binding, TAP transport efficiency, and proteasomal cleavage predictions. Eur J Immunol 2005;35:2295-303.

18. Yewdell JW, Bennink JR. Immunodominance in major histocompatibility complex class I-restricted $\mathrm{T}$ lymphocyte responses. Annu Rev Immunol 1999;17:51-88.

19. Riedl P, Reimann J, Schirmbeck R. Complexes of DNA vaccines with cationic, antigenic peptides are potent, polyvalent CD8 (+) T-cell-stimulating immunogens. Meth Mol Med 2006;127:159-69.

20. Brusic V, Bajic VB, Petrovsky N. Computational methods for prediction of T-cell epitopes-a framework for modelling, testing, and applications. Methods 2004;34:436-43.

21. De Groot AS, Moise L. Prediction of immunogenicity for therapeutic proteins: state of the art. Curr Opin Drug Discovery Dev 2007;10:332-40.

22. Rammensee H, Bachmann J, Emmerich NP, Bachor OA, Stevanovic S. SYFPEITHI: database for MHC ligands and peptide motifs. Immunogenetics 1999;50:213-9.

23. Yu K, Petrovsky N, Schonbach C, Koh JL, Brusic V. Methods for prediction of peptide binding to MHC molecules: a comparative study. Mol Med 2002;8:137-48.

24. Brusic V, Rudy G, Honeyman MC, Hammer J, Harrison LC. Prediction of MHC class-II binding peptides using an evolutionary algorithm and artificial neural network. Bioinformatics 1998;14:121-30.

25. Mamitsuka H. Predicting peptides that bind to MHC molecules using supervised learning of hidden Markov models. Proteins Struct Funct Genet 1998;33:460-74.
26. Lim JS, Kim S, Lee HG. Selection of peptides that bind to the HLA A2.1 molecule by molecular modeling. Mol Immunol 1996;33:221-30.

27. Rognan D, Lauemoller SL, Holm A, Buus S, Tschinke V. Predicting binding affinities of protein ligands from three dimensional models: application to peptide binding to class I major histocompatibility proteins. J Med Chem 1999;42:46508.

28. Parker KC, Bednarek MA, Coligan JE. Scheme for ranking potential HLA A2 binding peptides based on independent binding of individual peptide side chains. J Immunol 1994;152:163-75.

29. Reche PA, Glutting JP, Reinherz EL. Prediction of MHC class I binding peptides using pifide motifs. Hum Immunol 2002;63:701-8.

30. Donnes P, Elofsson A. Prediction of MHC class I binding peptides, using SVMHC. BMC Bioinformatics 2002;3:25-30.

31. Guan P, Doytchinova IA, Zygouri C, Flower DR. MHC pred: a server for quantitative prediction of peptide-MHC binding. Nucleic Acids Res 2003;31:3621-4.

32. Antonets DV, Maksyutov AZ. TEpredict: software for $\mathrm{T}$ cell epitope prediction. Mol Biol 2010;44:130-9.

33. Cohen T, Moise L, Martin W, De Groot AS. Immunoinformatics: the next step in vaccine design. In Infectious Disease Informatics, Springer New York; 2010. p. 223-44.

34. Eklund C, Afgeijersstam V, Yuan F, Stuber G, Dillner J. Identification of a cytotoxic T-lymphocyte epitope in the human papillomavirus type 16 E2 protein. J Gen Virol 1997;78:2615-20.

35. Liu DW, Yang YC, Lin HF, Lin MF, Cheng YW, Chu CC, et al. Cytotoxic T-lymphocyte responses to human papilloma virus type 16 E5 and E7 proteins and HLA-A* 0201-restricted T-cell peptides in cervical cancer patients. J Virol 2007;81:2869-79.

36. Zehbe I, Kaufmann AM, Schmidt M, Hohn H, Maeurer MJ. Human papilloma virus 16 E6-specific CD45RA+CCR7+high avidity CD8+T cells fail to control tumor growth despite interferon-[gamma] production in patients with cervical cancer. J Immunother 2007;30:523-32.

37. Matijevic M, Hedley ML, Urban RG, Chicz RM, Lajoie C, Luby TM. Immunization with a poly (lactide co-glycolide) encapsulated plasmid DNA expressing antigenic regions of HPV 16 and 18 results in an increase in the precursor frequency of $\mathrm{T}$ cells that respond to epitopes from HPV 16, 18, 6 and 11. Cell Immunol 2011;270:62-9.

38. Riemer AB, Keskin DB, Zhang G, Handley M, Anderson KS, Brusic V, et al. A conserved E7-derived cytotoxic T lymphocyte epitope expressed on human papilloma virus 16-transformed HLA-A2+epithelial cancers. J Biol Chem 2010;285:29608-22.

39. Hu J, Peng X, Schell TD, Budgeon LR, Cladel NM, Christensen ND. An HLA-A2. 1-transgenic rabbit model to study immunity to papilloma virus infection. J Immunol 2006;177:8037-45.

40. Daftarian PM, Mansour M, Pohajdak B, Fuentes-Ortega A, Korets-Smith E, MacDonald L, et al. Rejection of large HPV-16 expressing tumors in aged mice by a single immunization of VacciMax® encapsulated CTL/T helper peptides. J Trans Med 2007;5:26.

41. Yoon H, Chung MK, Min SS, Lee HG, Yoo WD, Chung KT, et al. Synthetic peptides of human papilloma virus type 18 E6 harboring HLA-A2. 1 motif can induce peptide-specific cytotoxic T-cells from peripheral blood mononuclear cells of healthy donors. Virus Res 1998;54:23-9.

42. Rudolf MP, Man S, Melief CJ, Sette A, Kast WM. Human T-cell responses to HLA-A-restricted high binding affinity peptides of human papillomavirus type 18 proteins E6 and E7. Clin Can Res 2001;7:788-95.

43. Huang L, Dai Y. Direct prediction of T-cell epitopes using support vector machines with novel sequence encoding schemes. J Bioinf Comput Biol 2006;4:93-107.

44. Liu Z, Lv H, Han J, Liu R. A computational model for predicting transmembrane regions of retroviruses. J Bioinf Comput Biol 2017; 15:17500-10.

45. Boesen A, Sundar K, Coico R. Lassa fever virus peptides predicted by computational analysis induce epitope-specific cytotoxic-T-lymphocyte responses in HLA-A2.1 transgenic mice. Clin Diagn Lab Immunol 2005;12:1223-30. 
46. Kirti, Pranav Kumar P. Human papilloma virus associated cervical cancer: a review. Asian J Pharm Clin Res 2016; 9:14-7.

47. Chozhavel Rajanathan TM, Lakshmikanth G, Agastian P. Evaluating the efficacy of aluminum phosphate formulated 12 based human papilloma virus vaccine. I Pharm Clin Res 2015;8:199-201.

48. Borappa M, Kanakarajan S, Kamalanathan A. In silico docking of quercetin compound against the hela cell line proteins. Int J Curr Pharm Res 2015;7:13-6. 